\title{
Extravehicular Activity Systems Education and Public Outreach in Support of NASA's STEM initiatives
}

\author{
Heather L. Paul ${ }^{1}$ \\ NASA Johnson Space Center, Houston, Texas 77058
}

\begin{abstract}
The exploration activities associated with NASA's goals to return to the Moon, travel to Mars, or explore Near Earth Objects (NEOs) will involve the need for human-supported space and surface extravehicular activities (EVAs). The technology development and human element associated with these exploration missions provide fantastic content to promote science, technology, engineering, and math (STEM). As NASA Administrator Charles F. Bolden remarked on December 9, 2009, "We...need to provide the educational and experiential stepping-stones to inspire the next generation of scientists, engineers, and leaders in STEM fields.” The EVA Systems Project actively supports this initiative by providing subject matter experts and hands-on, interactive presentations to educate students, educators, and the general public about the design challenges encountered as NASA develops EVA hardware for these missions. This paper summarizes these education and public efforts.
\end{abstract}

\footnotetext{
${ }^{1}$ EVA Systems Education and Public Outreach Lead, Space Suit and Crew Survival Systems Branch, 2101 NASA
} Parkway, Houston, Texas 77058. 


\title{
Extravehicular Activity Systems Education and Public Outreach in Support of NASA's STEM Initiatives
}

\author{
Heather L. Paul ${ }^{1}$ \\ NASA Johnson Space Center, Houston, Texas 77058
}

\begin{abstract}
The exploration activities associated with NASA's goals to return to the Moon, travel to Mars, or explore Near Earth Objects (NEOs) will involve the need for human-supported space and surface extravehicular activities (EVAs). The technology development and human element associated with these exploration missions provide fantastic content to promote science, technology, engineering, and math (STEM). As NASA Administrator Charles F. Bolden remarked on December 9, 2009, "We...need to provide the educational and experiential stepping-stones to inspire the next generation of scientists, engineers, and leaders in STEM fields.” The EVA Systems Project Office actively supports this initiative by providing subject matter experts and hands-on, interactive presentations to educate students, educators, and the general public about the design challenges encountered as NASA develops EVA hardware for these exploration missions. This paper summarizes the EVA Systems education and public efforts from fiscal year 2010.
\end{abstract}

\section{INTRODUCTION}

The Extravehicular Activity (EVA) Systems community at the NASA Johnson Space Center is dedicated to designing and developing the next generation of EVA technologies in support of NASA's goals for space exploration. The technology development and human element associated with these development efforts provide a unique opportunity to enhance NASA-sponsored education and public outreach (EPO) programs to stimulate interest in science, technology, engineering, and math (STEM) areas.

While EPO was conducted within EVA Systems prior to fiscal year 2010 (FY10), FY10 marked the first year in which EPO was an official position within the EVA Systems Project Office. As such, more emphasis was placed on the coordination, implementation, and tracking of EPO activities throughout the year. Products were developed for team use to provide consistent messaging to the EPO audience of students, educators, and the general public, and EPO events were tracked to collect metrics on several areas of interest including event location and audience demographics. This paper summarizes the EVA Systems education and public efforts from fiscal year 2010.

\section{DEFINITIONS: EPO ACTIVITIES AND AUDIENCE}

For the purposes of this paper, an EVA Systems EPO event or activity is classified as the following: EVA/Space suit demonstrations and presentations, media interviews, mentoring, EVA subject matter consultation, participation in integrated tests for imagery capture, and participation in the NASA Extreme Environments Mission Operations (NEEMO) 14 and Desert Research and Technology Studies (DRATS) analog missions. The EPO audience is comprised of students, educators, and the general public.

\section{EVA SYSTEMS EPO OBJECTIVES}

The goal of EVA Systems EPO is to support hands-on, interactive, educational experiences so that students of all ages and levels may learn about the design and operational challenges associated with EVA technologies developed in support of NASA exploration initiatives. These experiences relate to and impact students, by demonstrating how interests in science, technology, engineering, and math (STEM) can develop into future careers, and by reinforcing the concepts of the scientific method, teamwork, and critical thinking taught in the classroom. The activities under

\footnotetext{
${ }^{1}$ EVA Systems Education and Public Outreach Lead, Space Suit and Crew Survival Systems Branch, 2101 NASA Parkway, Houston, Texas 77058.
} 
way to develop EVA systems technologies and operations for future human exploration provide incredible, realworld content for EPO programs, stimulating interest in the space program, and bringing NASA's challenges to a tangible level for the EPO audience.

\section{COLLABORATIVE PARTNERS}

In FY10, EVA Systems EPO sought collaboration with the Education Office and the Public Affairs Office at NASA HQ and the Johnson Space Center (JSC), as well as with the Exploration Technology Development Project (ETDP). Additionally, EVA Systems EPO worked with the NASA Extreme Environments Mission Operations (NEEMO) 14 and Desert Research and Technology Studies (Desert RATS) analog missions.

\section{FISCAL YEAR 2010 EPO SUMMARY AND METRICS}

In FY10, EVA Systems EPO completed a total of 158 events. The majority of these events were live, interactive presentations covering EVA and/or space suit topics, presented in classrooms, auditoriums, public events, or via the web. Fifteen media interviews took place throughout the year, varying from radio, film, and news/magazines from the United States and the United Kingdom, resulting in multiple articles and features covering EVA topics and personnel. One mentoring opportunity was supported in which middle school students worked with a materials expert to determine the best materials for space suit design. Subject matter experts reviewed EVA-related information for educational curriculum and NASA websites, resulting in six consultations. Additionally, two integrated engineering tests were supported with photo/video imagery capture, and EVA systems EPO support was provided for the NEEMO 14 and DRATS analog missions. Table 1 shows the breakdown of the events by type for each quarter of the fiscal year. For comparison, in fiscal year 2009, a total of 72 events were completed and tracked. Therefore, FY10 resulted in a 219\% increase over the previous year's total number of EPO events!

\begin{tabular}{|c|c|c|c|c|c|}
\hline Event Type & $\begin{array}{c}\text { 1st Quarter } \\
\text { Events } \\
\text { (Oct - Dec) }\end{array}$ & $\begin{array}{c}\text { 2nd Quarter } \\
\text { Events } \\
\text { (Jan-Mar) }\end{array}$ & $\begin{array}{c}\text { 3rd Quarter } \\
\text { Events } \\
\text { (Apr- June) }\end{array}$ & $\begin{array}{c}\text { 4th Quarter } \\
\text { Events } \\
\text { (July - Sept) }\end{array}$ & $\begin{array}{c}\text { FY10 Total } \\
\text { Events }\end{array}$ \\
\hline EVA/Suit Demo & 15 & 18 & 64 & 35 & 132 \\
\hline Interview & 1 & 10 & 2 & 2 & 15 \\
\hline Mentoring & 1 & - & - & - & 1 \\
\hline Consultation & 1 & 5 & - & - & 6 \\
\hline Integrated Tests & - & 1 & 1 & 2 & 4 \\
\hline Total & 18 & 34 & 67 & 39 & 158 \\
\hline
\end{tabular}

Table 1. Summary of EVA Systems EPO events for FY10.

Figure 1 shows the EVA Systems EPO Events for each month of the fiscal year. Table 1 and Figure 1 show that events increased significantly for the last two months of the third quarter (May and June), and the first month of the fourth quarter (July). This trend is comparable to that experienced in previous years of supporting EPO events, as these months include a higher incidence of requests to support events related to end of school year activities, on-site NASA programs and facility tours that occur in the summer (such as Texas Aerospace Scholars), and off-site summer camps and schools. 


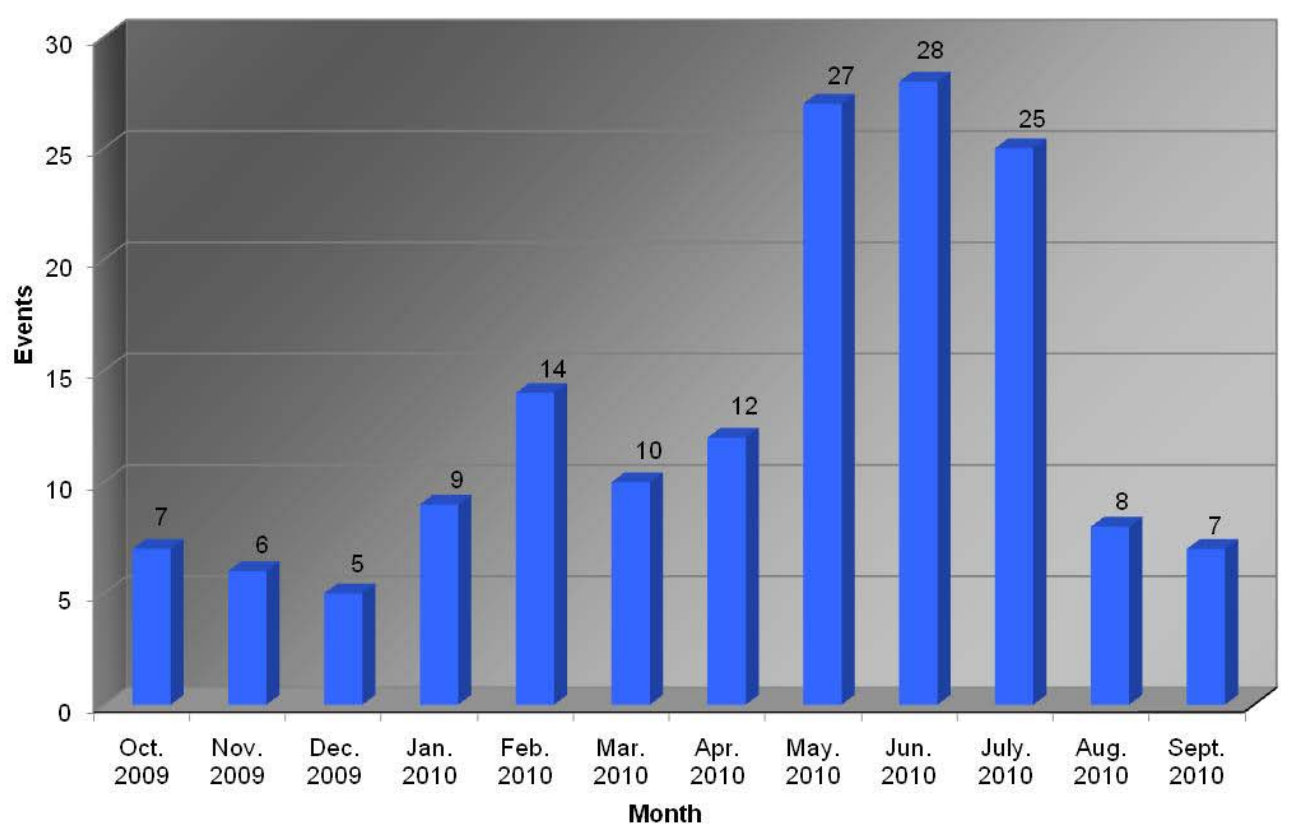

Figure 1. EVA Systems EPO Events Per Month

\section{METRICS BY LOCATION}

Of the 158 total EPO events in FY10, 132 were live, interactive EVA/space suit presentations conducted in classrooms, auditoriums, public events, or via the web. The location of a live event dictates whether it falls under the purview of the JSC Education Office or the Public Affairs Office. Tracking events by location not only ensures that EVA Systems EPO collaborates with the proper NASA offices, it also provides insight into what geographical areas we are reaching with our presentations.

Table 2 shows that the majority of presentations occurred at or within 50 miles of JSC. Sixteen events were supported outside of Houston, but within Texas, three events were beyond Texas but within the United States, and one international event was supported in Scotland (further details provided later in this paper).

\begin{tabular}{|c|c|c|c|c|c|c|}
\hline Location & $\begin{array}{c}\text { 1st Quarter } \\
\text { Presentations } \\
\text { (Oct-Dec) }\end{array}$ & $\begin{array}{c}\text { 2nd Quarter } \\
\text { Presentations } \\
\text { (Jan-Mar) }\end{array}$ & $\begin{array}{c}\text { 3rd Quarter } \\
\text { Presentations } \\
\text { (Apr-June) }\end{array}$ & $\begin{array}{c}\text { 4th Quarter } \\
\text { Presentations } \\
\text { (July-Sept) }\end{array}$ & $\begin{array}{c}\text { FY10 Total } \\
\text { Presentations }\end{array}$ & $\begin{array}{l}\text { FY10 Total } \\
\text { Percentages }\end{array}$ \\
\hline JSC B7/34 & - & 2 & 19 & 11 & 32 & $24 \%$ \\
\hline Within 50 Miles of JSC & 14 & 15 & 31 & 20 & 80 & $60 \%$ \\
\hline \begin{tabular}{|c|} 
Exceeding 50 Miles of \\
JSC, But in TX
\end{tabular} & 1 & 0 & 13 & 2 & 16 & $12 \%$ \\
\hline $\begin{array}{c}\text { Exceeding Texas, But in } \\
\text { US }\end{array}$ & - & 1 & - & 2 & 3 & $3 \%$ \\
\hline International & - & - & 1 & - & 1 & $1 \%$ \\
\hline Total & 15 & 18 & 64 & 35 & 132 & $100 \%$ \\
\hline
\end{tabular}

Table 2. Summary of EVA/space suit presentations by location.

\section{METRICS BY AUDIENCE TYPE}


In addition to tracking the location for the 132 live, interactive presentations, it is important to track the EPO audience for these events to identify what groups we are reaching with our presentations. Table 3 provides a summary of the audience participants for each quarter of FY10. Middle school denotes students in grades six through eight, and high school denotes grades nine through twelve. The general public category is used for events in which the audience was a combination of students and adults, and specific details on ages/grades was not available.

In the third quarter, the total audience value of 17,830 significantly exceeded that of the other quarters, equating to $76 \%$ of the total audience reached in FY10. The higher audience value correlates to the increased number of events supported during the third quarter. For comparison, the total audience participation in FY09 was 9,027, therefore the FY10 total audience value was 259\% higher than that of FY09!

\begin{tabular}{|c|c|c|c|c|c|c|}
\hline Audience Type & $\begin{array}{c}\text { 1st Quarter } \\
\text { Total } \\
\text { (Oct - Dec) }\end{array}$ & $\begin{array}{c}\text { 2nd Quarter } \\
\text { Total } \\
\text { (Jan - Mar) }\end{array}$ & $\begin{array}{c}\text { 3rd Quarter } \\
\text { Total } \\
\text { (Apr - June) }\end{array}$ & $\begin{array}{c}\text { 4th Quarter } \\
\text { Total } \\
\text { (July - Sept) }\end{array}$ & $\begin{array}{c}\text { FY10 } \\
\text { Total }\end{array}$ & $\begin{array}{c}\text { FY10 Total } \\
\text { Percentages }\end{array}$ \\
\hline K-5 & 500 & 577 & 3,795 & 230 & 5,102 & $21.8 \%$ \\
\hline Middle School & 595 & 508 & 2,710 & 300 & 4,113 & $17.6 \%$ \\
\hline High School & 85 & 53 & 1,879 & 445 & 2,462 & $10.5 \%$ \\
\hline College & 0 & 30 & 193 & 40 & 263 & $1.1 \%$ \\
\hline Educators & 0 & 89 & 0 & 165 & 254 & $1.1 \%$ \\
\hline General Public & 980 & 450 & 9,253 & 510 & 11,193 & $47.9 \%$ \\
\hline Total Audience & $\mathbf{2 , 1 6 0}$ & $\mathbf{1 , 7 0 7}$ & $\mathbf{1 7 , 8 3 0}$ & $\mathbf{1 , 6 9 0}$ & $\mathbf{2 3 , 3 8 7}$ & $\mathbf{1 0 0 \%}$ \\
\hline
\end{tabular}

Table 3. Summary of EVA/space suit presentations by audience type.

\section{FEATURED FY10 EPO EVENTS}

\section{Public Events}

Each year JSC opens its doors to the public as part of the Ballunar Liftoff Festival and JSC Open House. This event occurred on October 24, 2009, and the EVA Systems display was housed in the Saturn V building. The display included the Advanced Crew Escape Suit (ACES), the Extravehicular Mobility Unit (EMU), and an advanced suit mockup, as well as several posters and displays showing pictures of our technologies at work. Thirteen volunteers manned the display throughout the day, talking to students of all ages about EVA technology, and what NASA is building for future exploration. In addition to the static display, EVA Systems was included as a featured presentation for audiences in the Teague Auditorium. A total of 580 general public participants were tallied for the day, equating to approximately $59 \%$ of the total general public audience reached in the first quarter of FY10, and $27 \%$ of the total audience for the first quarter of FY10. Figures 2, 3, and 4 provide pictures from the event. 


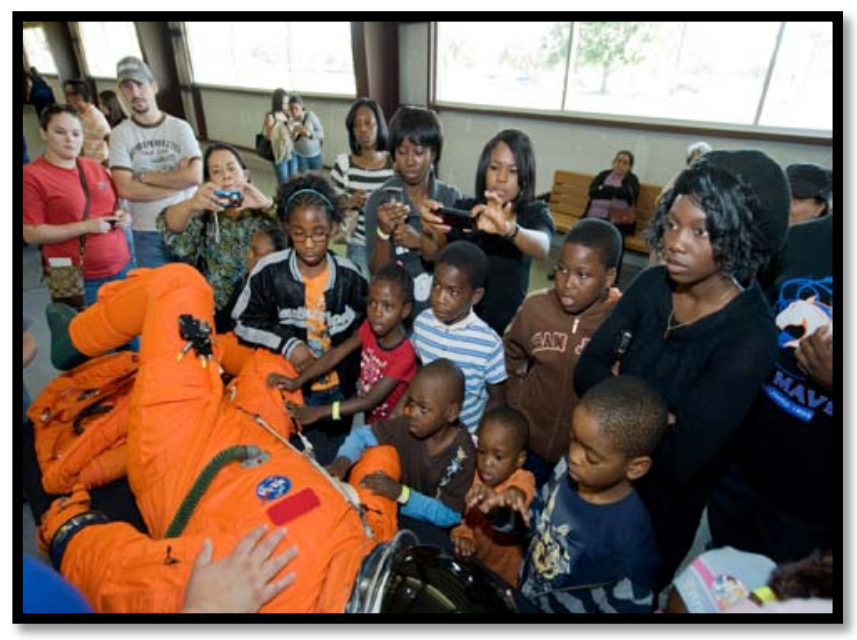

Figure 2. Students of all ages get a hands-on experience as volunteers pressurize the ACES and discuss mobility in the suit.

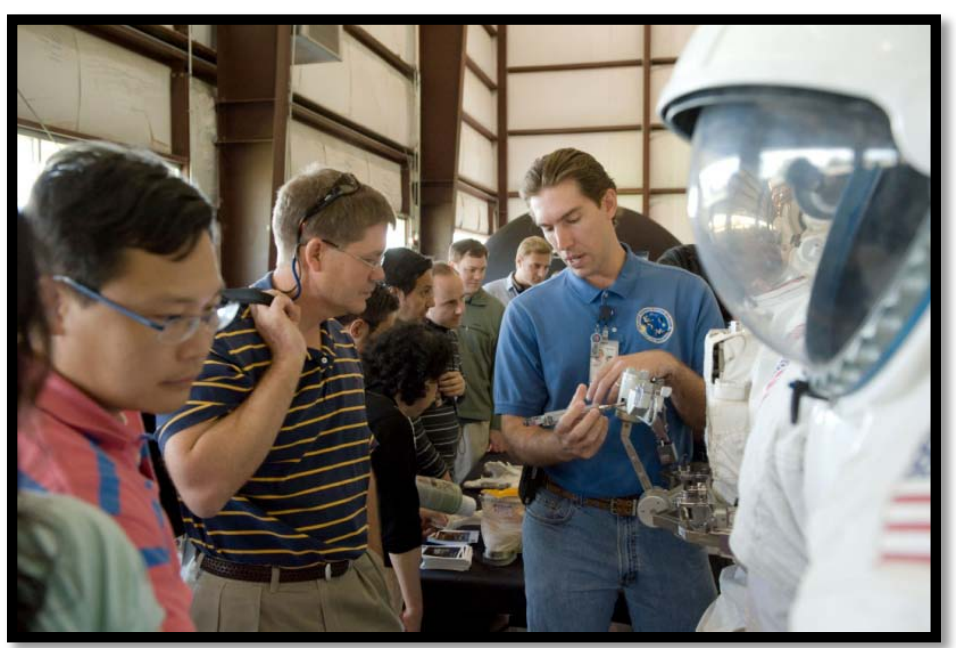

Figure 3. A NASA engineer explains EVA hardware to the general public at JSC Open House.

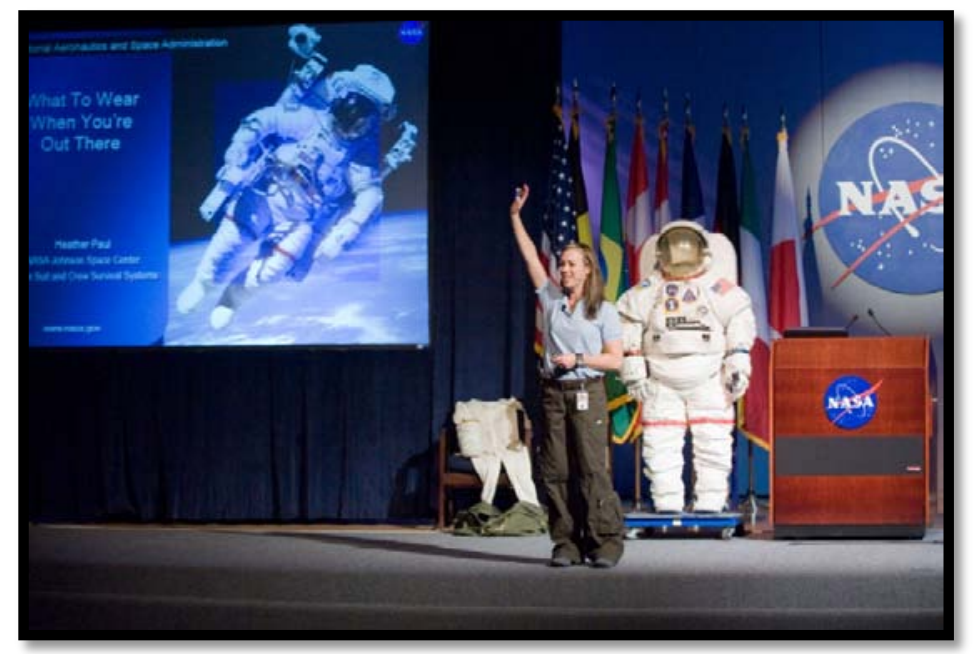

Figure 4. A NASA engineer conducts a featured EVA presentation at JSC Open House. 
In addition to JSC Open House, several other public events were supported throughout the year. ChristmasFest '09 was a NASA-supported event in downtown Houston on December 12, 2009. EVA Systems supported with six volunteers and EMU hardware. The event tallied 400 general public participants. Figures 5 and 6 show pictures from the event. Events at Texarkana College associated with commencement and Mini-NASCAR Race Day resulted in reaching out to over 7,000 general public participants.

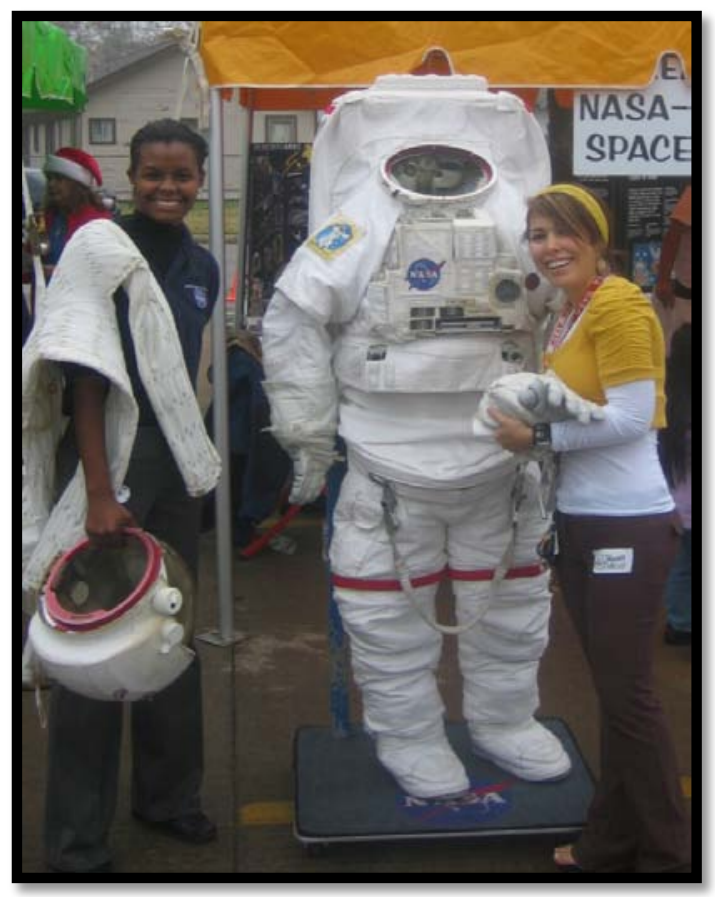

Figure 5. NASA engineers support the EMU display at ChristmasFest ’09.

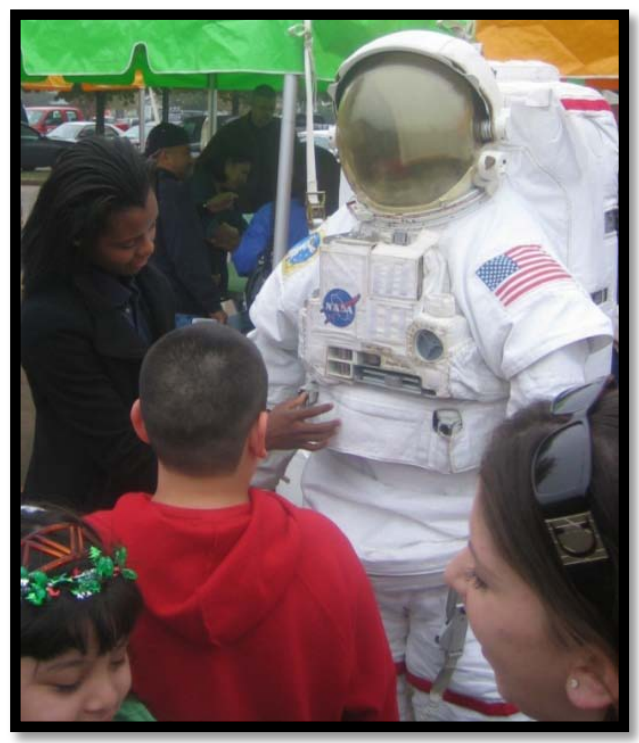

Figure 6. The general public gets a close-up look at the EMU.

\section{Reaching out to Educators}

The Space Exploration Educators Conference (SEEC) is an annual three-day conference hosted by Space Center Houston each February. The conference focuses on bringing educators together for a training opportunity, providing sessions on how to incorporate space topics into their educational curriculum. The EVA Systems EPO team presented at the 2010 conference, providing educators with information on NASA's space suit technologies, and 
recommendations on how to integrate EVA topics into the classroom environment. A total of 25 educators from around the United States attended the session, equating to approximately $28 \%$ of the total educator audience addressed in the second quarter of FY10, and 1.5\% of the total audience for the second quarter of FY10. Figures 7 and 8 provide pictures from the event.

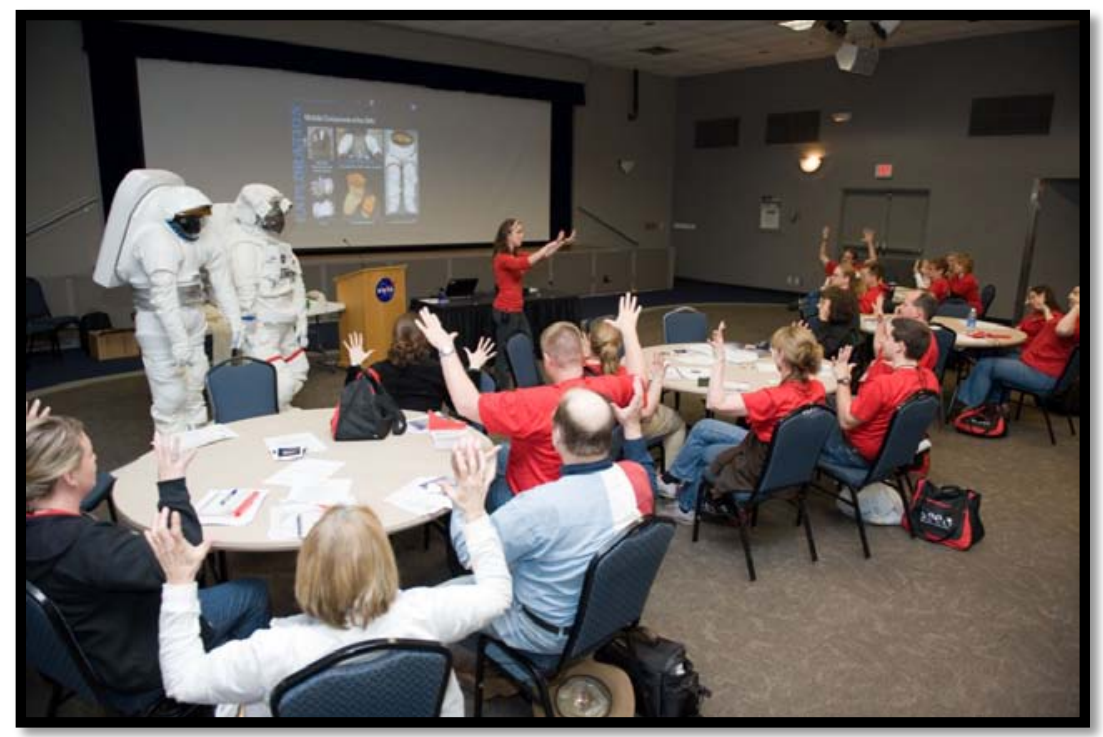

Figure 7. A NASA engineer explains the importance of gloves during EVA.

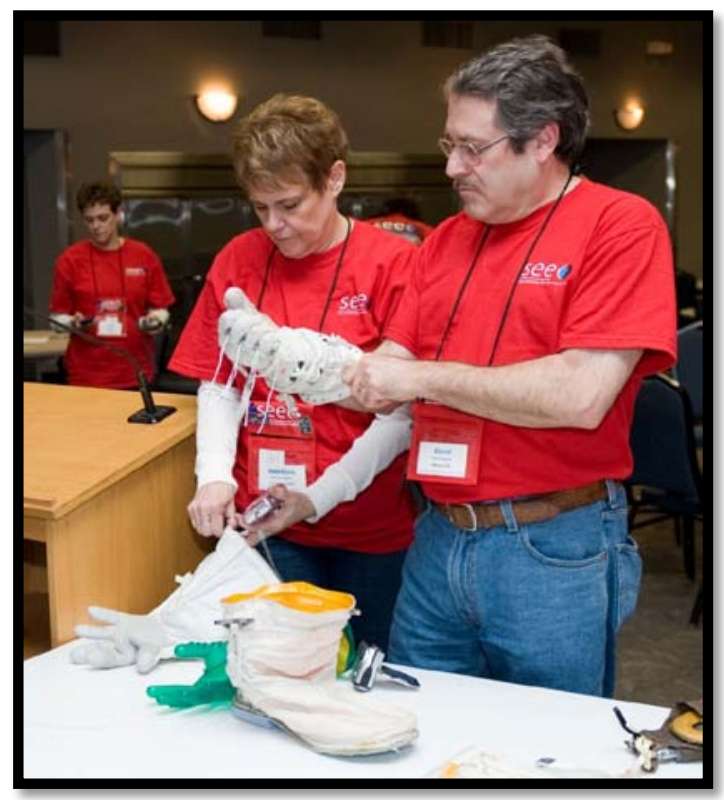

Figure 8. Educators gain hands-on experience with EMU hardware.

Going International with the Scottish Space School

From June 13-19, 2010, an EVA systems volunteer was teamed with a NASA astronaut, and the two conducted EPO presentations around Scotland as part of the Scottish Space School program. The primary focus of this program is to provide a unique learning opportunity for high school students from around the country. These students compete to participate in the program, and one of the awards is a trip to Glasgow for a one-week educational experience at the University of Strathclyde, featuring professional speakers and activities on topics from orbital mechanics, to human physiology, to NASA's space exploration efforts. The goal is to highlight the importance of science and engineering in the modern world. The EVA Systems volunteer interacted with these students throughout the week, and 
conducted a special presentation on her experiences getting a job at NASA, highlighting NASA's various student and career opportunities. The volunteer participated in "An Evening with NASA," an event that was open to multiple student groups and the local community, resulting in 350 participants. The EVA Systems volunteer and NASA astronaut presented to elementary and high school students, resulting in 540 student interactions. Finally, they participated in a web-based interactive event called the "GLOW meet" with 4,000 students from 82 schools around the country. Feedback from the Scottish Space School students indicates that the EVA System volunteer's participation in these events was greatly appreciated, as it provided an exciting opportunity to learn from a professional in the space industry, and multiple students were inspired to pursue degrees in engineering and science after this interaction.

\section{CONCLUSIONS}

This paper presents a summary of the EVA Systems EPO events and metrics for fiscal year 2010. The metrics indicate that FY10 far exceeded the number of events supported and audience participants from 2009, indicating that with dedicated, funded EPO resources, we were able to coordinate more support from our EVA Systems team to reach well beyond our capabilities of prior years. EVA Systems EPO support is planned for fiscal year 2011, and early metrics indicate that we will exceed our 2010 metrics with more EPO events and a greater number of audience participants.

\section{ACKNOWLEDGEMENTS}

The author would like to thank Lara Kearney from the JSC EVA Systems Project Office for her continued support of education and public outreach. 